UDK 514.18

\title{
CONTINUOUS BENDING OF MINIMAL SURFACES, FORMED BY MEANS OF PLANE CURVES OF COMPLEX CURVATURE
}

\author{
S. F. Pylypaka, M. M. Mukvich
}

National University of Life and Environmental Sciences of Ukraine. Ukraine.

Speciality of article: 131 - applied mechanics.

Corresponding authors: engmech_centre@twin.nauu.kiev.ua

Article history: Received - October 2019, Accepted - January 2020.

Bibl. 10, fig. 12, tabl. 0.

Abstract. Analytical description of an one-parameter set of an associated minimal surfaces formed under their continuous bending, using complex variable was made. To find the equation of isotropic lines, parametric equations of logarithmic spiral and evolvent of circle defined by functions of natural parameter with complex curvature were used. Isotropic lines parametric equations are obtained from the condition of differential arc of spatial curve equality to zero. Analytical description of minimal surfaces and connected minimal surfaces were made in complex space with isotropic lines of grid transfer.

Expressions of the first and second quadratic forms of generated minimal surfaces coefficients were found. It is shown that the mean curvature of formed minimal surfaces equals zero at all points.

We investigated that minimum surface and connected minimal surface, which are formed on the base of isotropic line with the help of a logarithmic spiral with curvature of complex value share common properties with appropriate curvature surfaces built using logarithmic spiral curvature of actual value. Using various methods of analytical description of isotropic lines with evolvent of circle with curvature of complex value, minimal surfaces that with the replacement of variable have common properties with a curvature, but different metric characteristics were constructed.

Analytical description of one-parameter set of associated minimal surfaces allows to control their shape for solving various applications. Parametric equations of minimal surfaces were found in the form of elementary functions, allowing to explore their geometric properties and differential characteristics to optimize engineering methods of technical forms and architectural constructions design.

Key words: one-parameter set of associated minimal surfaces, isotropic line, logarithmic spiral, evolvent of the circle, function of a complex variable, complex curvature, mean curvature of a surface.

\section{Introduction}

An important problem of modeling of continuous frame of engineering forms and architectural constructions is taking into consideration their geometric and differential characteristics.

That's why the most essential are the design methods of curves and surfaces under specified conditions [1-3], research of trajectory of material points motion on the surface of the technical forms $[4,5]$, means of applying images to curved surfaces [6].

\section{Formulation of problem}

The average curvature at all points of a minimal surface equals zero, which is a prerequisite for solving the problem of finding the smallest surface area, which passes through a given plane or spatial curve. The geometrical shape of minimal surface provides even distribution of efforts in the shell of surface and extra rigidity. [7]

The first researches of minimal surfaces are known from J. Lagrange's publications, he considered a practical problem [8]: "To find the smallest surface area that stretched to the specified contour" (1786). J. Lagrange concluded that the smallest surface area, given by the function must satisfy Euler-Lagrange equation [8]:

$$
\left(1+q^{2}\right) \frac{\partial^{2} z}{\partial x^{2}}-2 p q \frac{\partial^{2} z}{\partial x \partial y}+\left(1+p^{2}\right) \frac{\partial^{2} z}{\partial y^{2}}=0
$$

where: $p=\frac{\partial z}{\partial x}, q=\frac{\partial z}{\partial y}$.

G. Monge in 1776 found that the equality of mean curvature to zero is a prerequisite of minimal surface area.

Euler-Lagrange's differential equation (1) generally is not integrated so one of the modern research directions of minimal surfaces analytical description is to improve methods of numerical integration $[9,10]$.

In works [7, 11-13] for designing surfaces of technical forms and architectural constructions, graphoanalytical methods of surfaces construction close to 
minimal were developed. Geometric modeling of deformed sheet of parabolic reflector that takes a shape close to the minimum surface was made in the research [14].

A special area of research related to finding analytical description of minimal surfaces using the elementary functions is development of methods that use complex variable properties.

\section{Analysis of recent research results}

To find analytical description of minimal surfaces by means of complex variable it is necessary to find parametric equations of zero length isotropic lines [15].

The authors of the research [16, 17] found parametric equations for isotropic lines according to Weierstrass and Schwarz formulas only in some cases. Modeling of isotropic lines with the help of fundamental splines was considered in work [18]. The method of analytical description of minimal surfaces using isotropic curves that lie on the surfaces of rotation assigned to isometric grid lines was realized in works [19-21]. In work [22] for analytical description of isotropic lines parametric equations of logarithmic spiral defined by functions of natural parameter with real curvature were used.

The opportunity to study analytical description of isotropic lines and corresponding minimal surfaces using planar curves with complex curvature value is required.

\section{Purpose of research}

To find analytical description of isotropic lines using parametric equations of logarithmic spiral and evolvent of circle, defined by functions of natural parameter with the complex curvature. Using isotropic lines to find analytical description of one-parameter set of associated minimal surfaces formed at their continuous bending.

\section{Results of research}

Consider a plane curve, given by the complex curvature value:

$$
k(s)=\frac{1}{i \cdot a \cdot s},
$$

where: $a$ - parameter curve, $i$-imaginary unit, $s-$ the arc length of the curve.

If $a=-i$, then expression (2) define curvature of logarithmic spiral.

Curvature of a plane curve $k(s)$ is determined from the formula [23]:

$$
k(s)=\frac{d \varphi}{d s},
$$

where: $\varphi-$ angle between tangent curve and $x$-axis.

Calling the condition $\varphi(0)=0$, we get plane curvature equation [23] from natural parameter $s$ :

$$
\begin{aligned}
& x(s)=x(0)+\int_{0}^{s} \cos \left[\int_{0}^{s} k(s) d s\right] \cdot d s, \\
& y(s)=y(0)+\int_{0}^{s} \sin \left[\int_{0}^{s} k(s) d s\right] \cdot d s .
\end{aligned}
$$

Substituting the expression of complex curvature values (2) y (4), then under the conditions $x(0)=0 \mathrm{i}$ $y(0)=0$, get:

$$
\begin{aligned}
& x(s)=\frac{a \cdot s}{a^{2}-1} \cdot\left[a \cdot \operatorname{ch}\left(\frac{\ln s}{a}\right)-\operatorname{sh}\left(\frac{\ln s}{a}\right)\right], \\
& y(s)=\frac{i \cdot a \cdot s}{a^{2}-1} \cdot\left[-\operatorname{ch}\left(\frac{\ln s}{a}\right)+a \operatorname{sh}\left(\frac{\ln s}{a}\right)\right] .
\end{aligned}
$$

From condition [15] $\left(x^{\prime}\right)^{2}+\left(y^{\prime}\right)^{2}++\left(z^{\prime}\right)^{2}=0$ define the expression $z(s)=i \cdot s$ and write parametric equations of isotropic spatial lines:

$$
\begin{aligned}
& x(s)=\frac{a \cdot s}{a^{2}-1} \cdot\left[a \cdot \operatorname{ch}\left(\frac{\ln s}{a}\right)-\operatorname{sh}\left(\frac{\ln s}{a}\right)\right], \\
& y(s)=\frac{i \cdot a \cdot s}{a^{2}-1} \cdot\left[-\operatorname{ch}\left(\frac{\ln s}{a}\right)+a \operatorname{sh}\left(\frac{\ln s}{a}\right)\right], \\
& z(s)=i \cdot s .
\end{aligned}
$$

To find the equations of minimal and associated minimal surface, it is necessary to introduce replacement in isotropic curve parametric equations (6) [22]: $s=u+i \cdot v$. Then we get parametric equations of minimal surface $X(u, v), Y(u, v), Z(u, v)$ :

$$
\begin{aligned}
& X(u, v)=\operatorname{Re}\{x(u+i \cdot v)\}, \\
& Y(u, v)=\operatorname{Re}\{y(u+i \cdot v)\}, \\
& Z(u, v)=\operatorname{Re}\{i \cdot(u+i \cdot v)\},
\end{aligned}
$$

and associated minimal surface $X^{*}(u, v), Y^{*}(u, v)$, $Z^{*}(u, v)$ :

$$
\begin{aligned}
& X^{*}(u, v)=\operatorname{Im}\{x(u+i \cdot v)\}, \\
& Y^{*}(u, v)=\operatorname{Im}\{y(u+i \cdot v)\}, \\
& Z^{*}(u, v)=\operatorname{Im}\{i \cdot(u+i \cdot v)\} .
\end{aligned}
$$

Separating real and imaginary parts for each function (6), according to (7), (8), get the equation of minimal surface:

$$
\begin{aligned}
& \begin{aligned}
& X(u, v)= \frac{a}{a^{2}-1} \cdot[u \cdot \cos (\beta) \cdot(a \operatorname{ch} \gamma-\operatorname{sh} \gamma)- \\
&-v \cdot \sin (\beta) \cdot(a \operatorname{sh} \gamma-\operatorname{ch} \gamma)], \\
& Y(u, v)= \frac{a}{a^{2}-1} \cdot[v \cdot \cos (\beta) \cdot(a \operatorname{sh} \gamma-\operatorname{ch} \gamma)+ \\
&\quad+u \cdot \sin (\beta) \cdot(a \operatorname{ch} \gamma-\operatorname{sh} \gamma)],
\end{aligned} \\
& Z(u, v)=-v,
\end{aligned}
$$


where: $\beta=\beta(u ; v)=\frac{1}{a} \operatorname{arctg}\left(\frac{v}{u}\right)$,

$$
\gamma=\gamma(u ; v)=\frac{\ln \left(u^{2}+v^{2}\right)}{2 a},
$$

and associated minimal surface:

$$
\begin{aligned}
& \begin{aligned}
X^{*}(u, v)= & \frac{a}{a^{2}-1} \cdot[v \cdot \cos (\beta) \cdot(a \operatorname{ch} \gamma-\operatorname{sh} \gamma)+ \\
& +u \cdot \sin (\beta) \cdot(a \operatorname{sh} \gamma-\operatorname{ch} \gamma)],
\end{aligned} \\
& \begin{aligned}
Y^{*}(u, v)= & \frac{a}{a^{2}-1} \cdot[u \cdot \cos (\beta) \cdot(-a \operatorname{sh} \gamma+\operatorname{ch} \gamma)+ \\
& \quad+v \cdot \sin (\beta) \cdot(a \operatorname{ch} \gamma-\operatorname{sh} \gamma)],
\end{aligned} \\
& Z^{*}(u, v)=u,
\end{aligned}
$$

where: $\beta(u ; v)=\frac{1}{a} \operatorname{arctg}\left(\frac{v}{u}\right), \gamma(u ; v)=\frac{\ln \left(u^{2}+v^{2}\right)}{2 a}$.

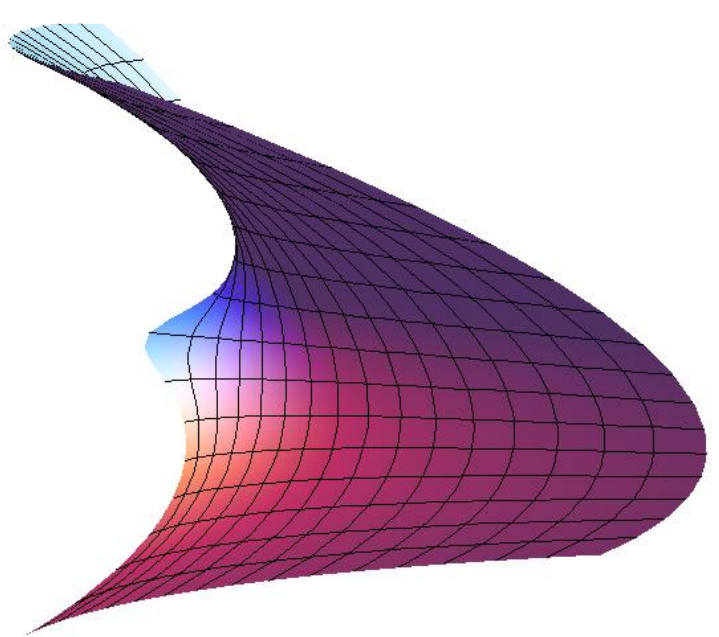

Fig. 1. Minimal surface built on equations (9).

In Fig. 1 minimal surface is shown, in Fig. 2 associated minimal surface is shown, which were built according to equations (9), (10) accordingly at $a=0,9$, $u \in(0 ; 4], v \in[-3 ; \ldots 3]$.

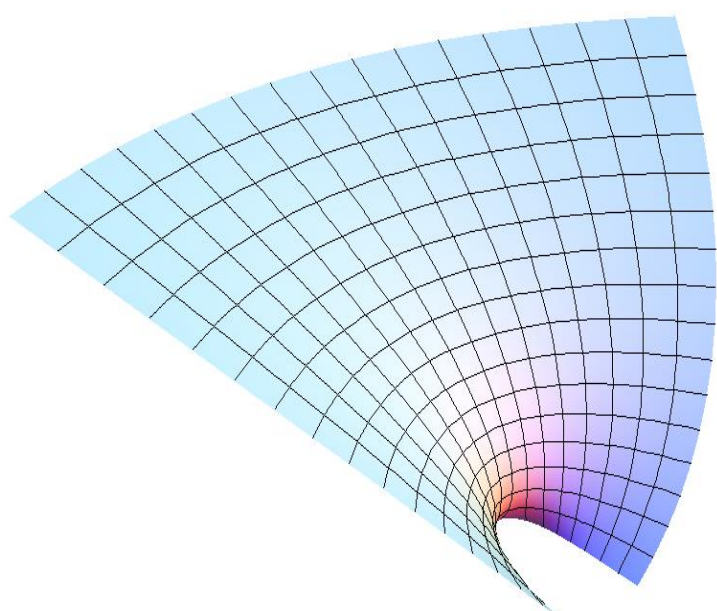

Fig. 2. Associated minimal surface built on equations (10).
We find coefficients of the first quadratic form of surface $X(u, v), Y(u, v), Z(u, v)$, which define metric properties of the surface according to the formulas [23]:

$$
\begin{aligned}
& E=\left(X_{u}^{\prime}\right)^{2}+\left(Y_{u}^{\prime}\right)^{2}+\left(Z_{u}^{\prime}\right)^{2}, \\
& F=X_{u}^{\prime} \cdot X_{v}^{\prime}+Y_{u}^{\prime} \cdot Y_{v}^{\prime}+Z_{u}^{\prime} \cdot Z_{v}^{\prime}, \\
& G=\left(X_{v}^{\prime}\right)^{2}+\left(Y_{v}^{\prime}\right)^{2}+\left(Z_{v}^{\prime}\right)^{2} .
\end{aligned}
$$

The coefficients of the first quadratic form of minimal surface (9) and the associated surface (10) equal to:

$$
E=G=\left[\frac{\ln \left(u^{2}+v^{2}\right)}{2 a}\right]^{2}, F=0 .
$$

We find expressions of a second quadratic form of surface $X(u, v), Y(u, v), Z(u, v)$, that define the surface curvature properties of according to the formulas [23]:

$$
\begin{aligned}
& L=\frac{1}{\sqrt{E G-F^{2}}} \cdot\left|\begin{array}{ccc}
X_{u u}^{\prime \prime} & Y_{u u}^{\prime \prime} & Z_{u u}^{\prime \prime} \\
X_{u}^{\prime} & Y_{u}^{\prime} & Z_{u}^{\prime} \\
X_{v}^{\prime} & Y_{v}^{\prime} & Z_{v}^{\prime}
\end{array}\right|, \\
& M=\frac{1}{\sqrt{E G-F^{2}}} \cdot\left|\begin{array}{ccc}
X_{u v}^{\prime \prime} & Y_{u v}^{\prime \prime} & Z_{u v}^{\prime \prime} \\
X_{u}^{\prime} & Y_{u}^{\prime} & Z_{u}^{\prime} \\
X_{v}^{\prime} & Y_{v}^{\prime} & Z_{v}^{\prime}
\end{array}\right|, \\
& N=\frac{1}{\sqrt{E G-F^{2}}} \cdot\left|\begin{array}{ccc}
X_{v v}^{\prime \prime} & Y_{v v}^{\prime \prime} & Z_{v v}^{\prime \prime} \\
X_{u}^{\prime} & Y_{u}^{\prime} & Z_{u}^{\prime} \\
X_{v}^{\prime} & Y_{v}^{\prime} & Z_{v}^{\prime}
\end{array}\right|,
\end{aligned}
$$

The coefficients of the second quadratic form of minimal surface (9) equal to:

$$
L=-N=-\frac{v}{a\left(u^{2}+v^{2}\right)}, M=\frac{u}{a\left(u^{2}+v^{2}\right)} .
$$

The coefficients of the second quadratic form of associated minimal surface (10) equal to:

$$
L^{*}=-N^{*}=-\frac{u}{a\left(u^{2}+v^{2}\right)}, M^{*}=-\frac{v}{a\left(u^{2}+v^{2}\right)} .
$$

The coefficients of the first and second quadratic forms of the constructed minimal surfaces (9) and (10), turn the expression of mean curvature $H=\frac{E \cdot N-2 \cdot F \cdot M+G \cdot L}{2\left(E \cdot G-F^{2}\right)}$ for each of the specified surfaces to zero.

Comparing expressions of coefficients of quadratic forms, it should be noted that for isotropic line (2) with complex curvature constructed minimal surfaces (9) and (10) that have common properties curvature but different metric properties of minimal surfaces formed by the study [22] with isotropic curve found based on parametric equations logarithmic spiral.

Minimal surfaces built on equations (9) and (10) have the same expression (12) of coefficients of the first quadratic form, that's why they allow continuous bending one above the other. Equations of one-parameter set of 
associated minimal surfaces formed with continuous bending are of the form [22]:

$$
\begin{aligned}
& X_{\varphi}(u, v)=X(u, v) \cos \varphi+X^{*}(u, v) \sin \varphi, \\
& Y_{\varphi}(u, v)=Y(u, v) \cos \varphi+Y^{*}(u, v) \sin \varphi, \\
& Z_{\varphi}(u, v)=Z(u, v) \cos \varphi+Z^{*}(u, v) \sin \varphi,
\end{aligned}
$$

where: $\quad X(u, v), Y(u, v), Z(u, v)-\quad$ parametric equations of minimal surface $X^{*}(u, v), Y^{*}(u, v), Z^{*}(u, v)-$ parametric equations of associated minimal surface (10), $\varphi$ - bending parameter of surfaces, $\varphi \in\left[0 ; \frac{\pi}{2}\right]$.

It is obviously that $\varphi=0$ equations (14) define the minimal surface (9), at $\varphi=\frac{\pi}{2}$ equations (14) define the associated minimal surface (10), for other values $\varphi \in\left(0 ; \frac{\pi}{2}\right)$ equations (14) define associated minimal surfaces [19].

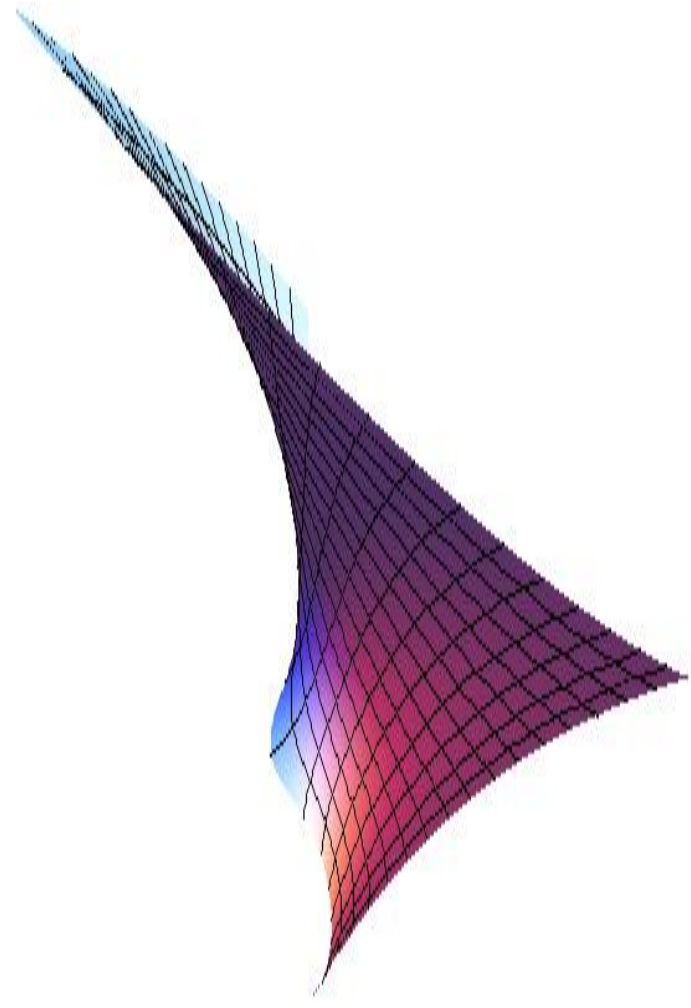

Fig. 3. Associated minimal surface built on equations (14) in accordance with $\varphi=\frac{\pi}{4}$.

In Fig. 3 we show a minimal associated surface constructed on equations (14) in accordance with $\varphi=\frac{\pi}{4}$ $, a=0,9, u \in(0 ; 4], v \in[-3 ; \ldots 3]$.

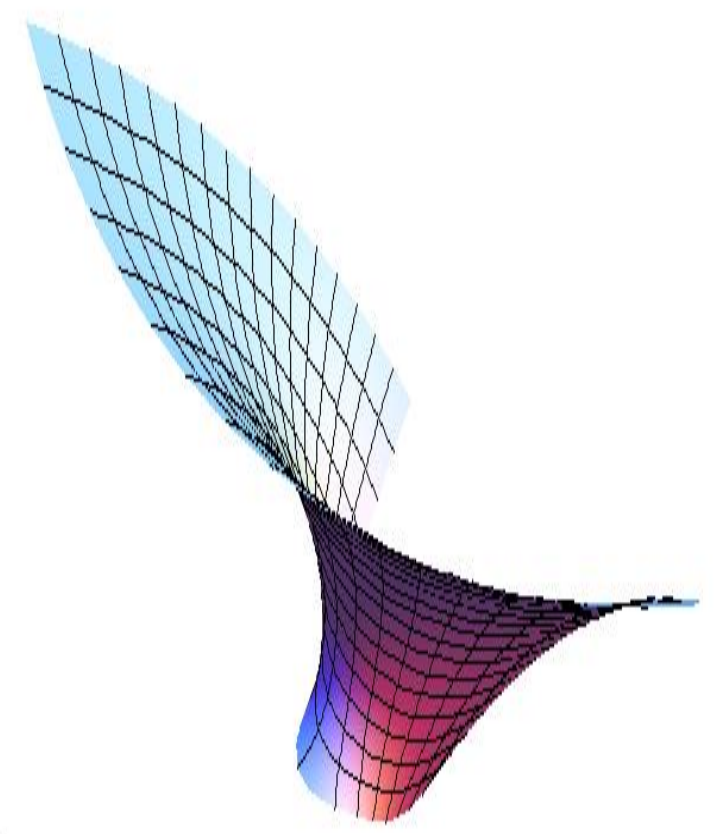

Fig. 4. Associated minimal surface built on equations (14) in accordance with $\varphi=\frac{3 \pi}{8}$.

All associated minimal surfaces have equal corresponding expressios (12) of the first quadratic form coefficients.

Consider a plane curve, given by complex value of the curvature:

$$
k(s)=\frac{1}{\sqrt{2 a \cdot i \cdot s}},
$$

where: $a-$ the parameter curve, $i-$ imaginary unit, $s-$ arc length of a curve.

If $a=-i$, then expression (15) specifies the curvature of evolvent of a circle. Substitute the value of complex curvature (15) in (4), then under meeting the conditions $x(0)=0$ and $y(0)=0$, obtain:

$$
\begin{aligned}
& x(s)=i \cdot a\left[\cos \sqrt{-\frac{2 i s}{a}}+\sqrt{-\frac{2 i s}{a}} \sin \sqrt{-\frac{2 i s}{a}}\right], \\
& y(s)=-i \cdot a\left[\sqrt{-\frac{2 i s}{a}} \cos \sqrt{-\frac{2 i s}{a}}-\sin \sqrt{-\frac{2 i s}{a}}\right] . \\
& \text { From condition }\left(x^{\prime}\right)^{2}+\left(y^{\prime}\right)^{2}+\left(z^{\prime}\right)^{2}=0
\end{aligned}
$$
define the expression $z(s)=i \cdot s$ and write the parametric equations of a spatial isotropic line:

$$
\begin{aligned}
& x(s)=i \cdot a\left[\cos \sqrt{-\frac{2 i s}{a}}+\sqrt{-\frac{2 i s}{a}} \sin \sqrt{-\frac{2 i s}{a}}\right], \\
& y(s)=-i \cdot a\left[\sqrt{-\frac{2 i s}{a}} \cos \sqrt{-\frac{2 i s}{a}}-\sin \sqrt{-\frac{2 i s}{a}}\right],
\end{aligned}
$$

$$
z(s)=i \cdot s
$$

To find the equations of minimal and associated minimal surface it is necessary to change parametric 
equations of isotropic curve (17) [22]: $s=u+i \cdot v$. Then, we will obtain a parametric equations of minimal surfaces $X_{1}(u, v), Y_{1}(u, v), Z_{1}(u, v)$ :

$$
\begin{aligned}
& X_{1}=-a \cdot m \cdot \operatorname{ch}(m \cdot \sin \alpha) \cdot \sin \alpha \cdot \sin (m \cdot \cos \alpha)+ \\
&+a \operatorname{sh}(m \sin \alpha) \times \\
& \times[\sin (m \cdot \cos \alpha)-m \cdot \cos \alpha \cdot \cos (m \cos \alpha)], \\
& Y_{1}=-a \cdot m \cdot \operatorname{ch}(m \cdot \sin \alpha) \cdot \sin \alpha \cdot \cos (m \cdot \cos \alpha)+ \\
&+a \operatorname{sh}(m \sin \alpha) \times \\
& \times[\cos (m \cos \alpha)+m \cos \alpha \sin (m \cos \alpha)], \\
& Z_{1}(u, v)=-v,
\end{aligned}
$$$$
\text { where: } m=m(u ; v)=\sqrt{2}\left(\frac{u^{2}+v^{2}}{a^{2}}\right)^{\frac{1}{4}} \text {, }
$$$$
\alpha=\alpha(u ; v)=-\frac{1}{2} \operatorname{arctg}\left(\frac{u}{v}\right)
$$

and associated minimal surface $X_{1}^{*}(u, v)$, $Y_{1}^{*}(u, v), Z_{1}^{*}(u, v)$ :

$$
\begin{aligned}
X_{1}^{*}= & -a \cdot m \cdot \operatorname{sh}(m \cdot \sin \alpha) \sin \alpha \cdot \cos (m \cdot \cos \alpha)+ \\
& +a \cdot \operatorname{ch}(m \sin \alpha) \times \\
& \times[\cos (m \cdot \cos \alpha)+m \cdot \cos \alpha \cdot \sin (m \cdot \cos \alpha)] \\
Y_{1}^{*}= & a \cdot m \cdot \operatorname{sh}(m \cdot \sin \alpha) \cdot \sin \alpha \cdot \sin (m \cdot \cos \alpha)+ \\
& +a \operatorname{ch}(m \sin \alpha) \times \\
& \times[-\sin (m \cdot \cos \alpha)+m \cdot \cos \alpha \cdot \cos (m \cos \alpha)] ; \\
Z_{1}^{*}= & u .
\end{aligned}
$$

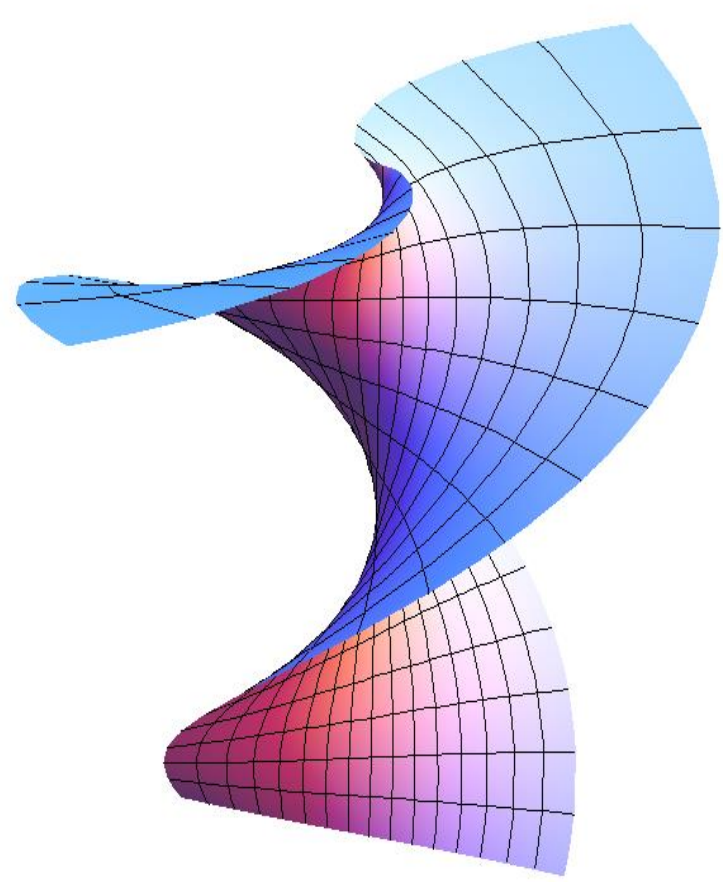

Fig. 5. Minimal surface built on equations (18)

In Fig. 5 a minimal surface is shown, Fig. 6 shows an associated minimal surface, that are built on equations
(18), (19) in accordance with $a=0,5, \quad u \in[-3 ; \ldots 3]$, $v \in(0 ; 16]$.

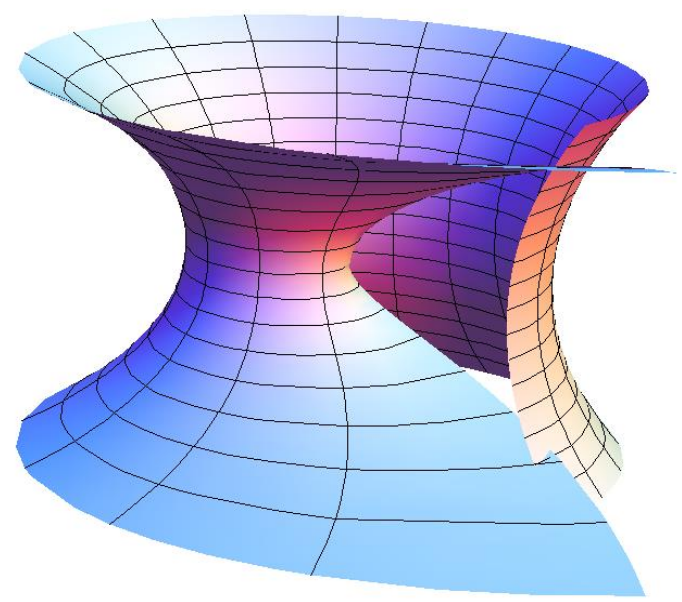

Fig. 6. Associated minimal surface built on equations (19).

The coefficients of the first quadratic form of minimal surface (18) and the associated surface (19) found by formula (11) equal to:

$E=G=\operatorname{ch}^{2}\left[\sqrt{2}\left(\frac{u^{2}+v^{2}}{a^{2}}\right)^{\frac{1}{4}} \sin \left(\frac{1}{2} \operatorname{arctg} \frac{u}{v}\right)\right]$

$F=0$.

The coefficients of the second quadratic form of minimal surface (18) found by formula (13) equal to:

$$
\begin{aligned}
& L=-N=\frac{v}{2\left(u^{2}+v^{2}\right)} \cdot \sqrt{2+\frac{2 u^{2}}{v^{2}}\left(\frac{u^{2}+v^{2}}{a^{2}}\right)^{\frac{1}{4}} \times} \\
& \times\left[\left(v^{2}-u^{2}\right) \sin \left(\frac{3}{2} \operatorname{arctg} \frac{u}{v}\right)-2 u v \cos \left(\frac{3}{2} \operatorname{arctg} \frac{u}{v}\right)\right], \\
& M=\frac{-v}{2\left(u^{2}+v^{2}\right)} \cdot \sqrt{2+\frac{2 u^{2}}{v^{2}}\left(\frac{u^{2}+v^{2}}{a^{2}}\right)^{\frac{1}{4}} \times} \\
& \times\left[\left(v^{2}-u^{2}\right) \cos \left(\frac{3}{2} \operatorname{arctg} \frac{u}{v}\right)+2 u v \sin \left(\frac{3}{2} \operatorname{arctg} \frac{u}{v}\right)\right] .
\end{aligned}
$$

The coefficients of the second quadratic form of associated minimal surface (19) equal to: $L^{*}=-N^{*}=-M, M^{*}=-L$,

where: $M$ and $L$ - the coefficients of the second quadratic form of minimal surface (18).

The coefficients of the first and second quadratic forms of the constructed minimal surfaces (18) and (19), turn the expression of mean curvature $H=\frac{E \cdot N-2 \cdot F \cdot M+G \cdot L}{2\left(E \cdot G-F^{2}\right)}$ for each of the specified surfaces to zero. 
Minimal surfaces built on equations (18) and (19) have equal expressions (20) of the first quadratic form, that's why they allow continuous bending one upon the other. Equation of a one-parameter set of associated minimal surfaces formed under continuous bending are of the form [22]:

$$
\begin{aligned}
& X_{\varphi}(u, v)=X_{1}(u, v) \cos \varphi+X_{1}^{*}(u, v) \sin \varphi ; \\
& Y_{\varphi}(u, v)=Y_{1}(u, v) \cos \varphi+Y_{1}^{*}(u, v) \sin \varphi ; \\
& Z_{\varphi}(u, v)=Z_{1}(u, v) \cos \varphi+Z_{1}^{*}(u, v) \sin \varphi,
\end{aligned}
$$

where: $X_{1}(u, v) ; Y_{1}(u, v) ; Z_{1}(u, v)-$ parametric equations of minimal surface (18),

$$
X_{1}^{*}(u, v) ; Y_{1}^{*}(u, v) ; Z_{1}^{*}(u, v)-
$$
parametric equations of associated minimal surface (19),

$$
\varphi-\text { bending parameter of surfaces, } \varphi \in\left[0 ; \frac{\pi}{2}\right] \text {. }
$$

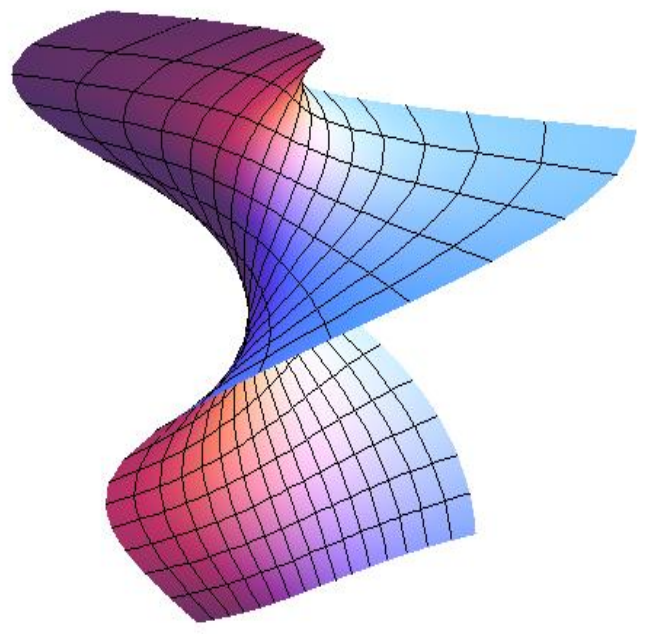

Fig. 7. Associated minimal surface built at $\varphi=\frac{\pi}{8}$.

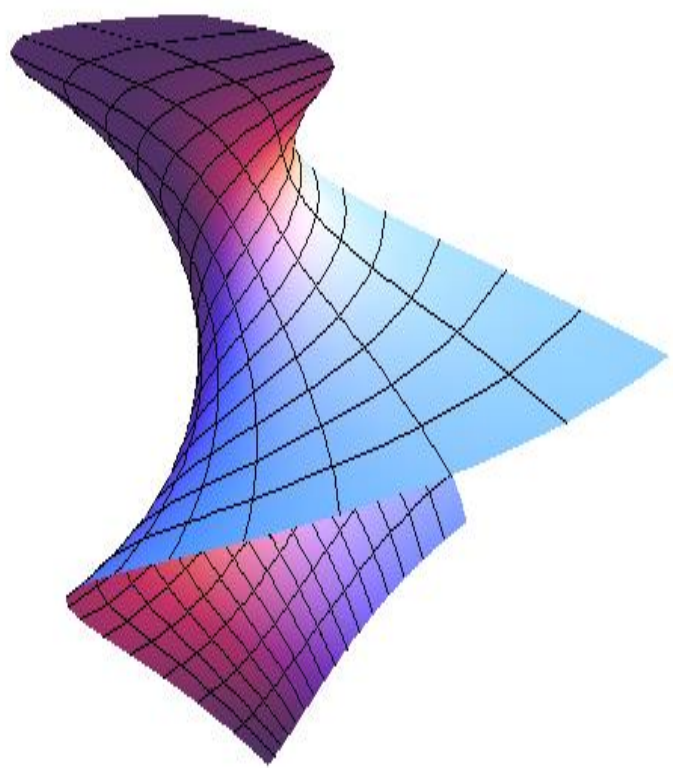

Fig. 8. Associated minimal surface built at $\varphi=\frac{\pi}{4}$.
At $\varphi=0$ equations (21) define minimal surface (18), at $\varphi=\frac{\pi}{2}$ equations (21) define associated minimal surface (19), at other values $\varphi \in\left(0 ; \frac{\pi}{2}\right)$ equations (21) define associated minimal surfaces [19].

In Fig. 7, Fig. 8, Fig. 9, Fig. 10 images associated minimal surfaces built on equations (21) in accordance for $a=0,9, \quad u \in[-3 ; \ldots 3], \quad v \in(0 ; 10]$, at $\varphi=\frac{\pi}{8}$, $\varphi=\frac{\pi}{6}, \varphi=\frac{\pi}{4}, \varphi=\frac{3 \pi}{8}$ respectively are built. These minimal surfaces are formed under continuous bending of a minimal surface (18) to attached minimal surface (19).

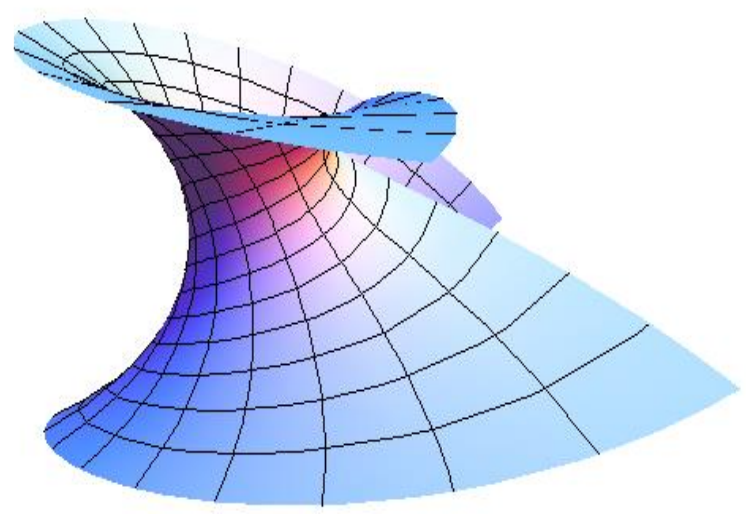

Fig. 9. Associated minimal surface built at $\varphi=\frac{\pi}{3}$.

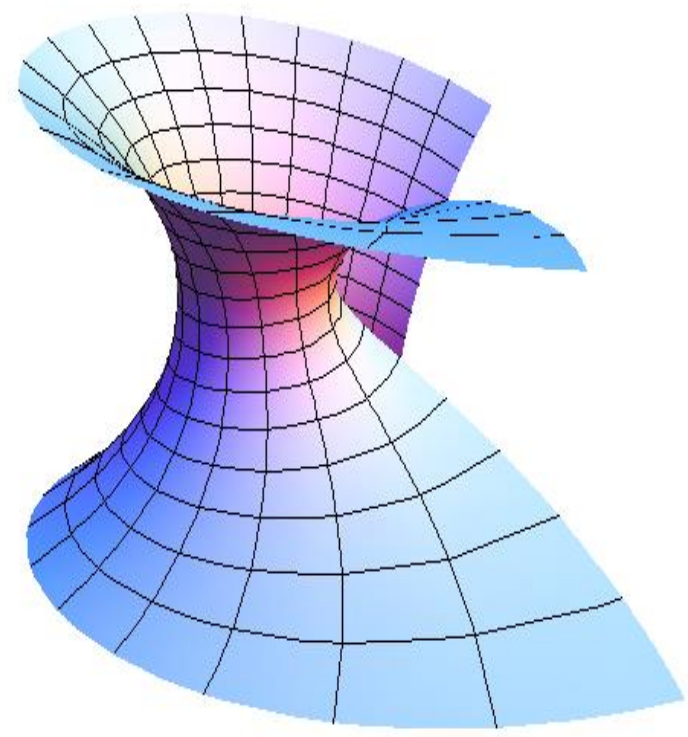

Fig. 10. Associated minimal surface built at $\varphi=\frac{3 \pi}{8}$. 
All built associated minimal surfaces have equal corresponding expressions (20) of the first quadratic form coefficients.

Consider a plane curve, given by complex value of the curvature:

$$
k(s)=\frac{i}{\sqrt{2 a \cdot i \cdot s}},
$$

where: $a-$ the parameter curve, $i-$ imaginary unit, $s-$ arc length of a curve.

Substitute the value of complex curvature (22) in (4), then under meeting the conditions $x(0)=0$ and $y(0)=0$, obtain:

$$
\begin{aligned}
& x(s)=a\left[-\operatorname{ch} \sqrt{\frac{2 s}{a}}+\sqrt{\frac{2 s}{a}} \cdot \operatorname{sh} \sqrt{\frac{2 s}{a}}\right] \\
& y(s)=i \cdot a\left[\sqrt{\frac{2 s}{a}} \cdot \operatorname{ch} \sqrt{\frac{2 s}{a}}-\operatorname{sh} \sqrt{\frac{2 s}{a}}\right] .
\end{aligned}
$$

From condition $\left(x^{\prime}\right)^{2}+\left(y^{\prime}\right)^{2}+\left(z^{\prime}\right)^{2}=0 \quad[15, \mathrm{p}$. 14] define the expression $z(s)=i \cdot s$ and write the parametric equations of a spatial isotropic line:

$$
\begin{aligned}
& x(s)=a\left[-\operatorname{ch} \sqrt{\frac{2 s}{a}}+\sqrt{\frac{2 s}{a}} \cdot \operatorname{sh} \sqrt{\frac{2 s}{a}}\right] ; \\
& y(s)=i \cdot a\left[\sqrt{\frac{2 s}{a}} \cdot \operatorname{ch} \sqrt{\frac{2 s}{a}}-\operatorname{sh} \sqrt{\frac{2 s}{a}}\right] ; \\
& z(s)=i \cdot s
\end{aligned}
$$

To find the equations of minimal and associated minimal surface it is necessary to change parametric equations of isotropic curve (24) [22]: $s=u+i \cdot v$. Then, we will obtain a parametric equations of minimal surfaces $X_{2}(u, v), Y_{2}(u, v), Z_{2}(u, v)$ :

$$
\begin{aligned}
& X_{2}= a \cdot m \cdot \operatorname{sh}(m \cdot \cos \alpha) \cdot \cos \alpha \cdot \cos (m \cdot \sin \alpha)- \\
&-a \cdot \operatorname{ch}(m \cdot \cos \alpha) \times \\
& \times[\cos (m \cdot \sin \alpha)+m \cdot \sin \alpha \cdot \sin (m \sin \alpha)], \\
& Y_{2}=-a \cdot m \cdot \operatorname{sh}(m \cdot \cos \alpha) \cdot \cos \alpha \cdot \sin (m \cdot \sin \alpha)+ \\
&+a \cdot \operatorname{ch}(m \sin \alpha) \times \\
& \times[\sin (m \cos \alpha)-m \sin \alpha \cos (m \sin \alpha)], \\
& Z_{2}(u, v)=-v,
\end{aligned}
$$

where: $m=m(u ; v)=\sqrt{2}\left(\frac{u^{2}+v^{2}}{a^{2}}\right)^{\frac{1}{4}}$,

$$
\alpha=\alpha(u ; v)=-\frac{1}{2} \operatorname{arctg}\left(\frac{v}{u}\right)
$$

and associated minimal surface $X_{2}{ }^{*}(u, v)$, $Y_{2}^{*}(u, v), Z_{2}^{*}(u, v)$ :

$$
\begin{aligned}
X_{2}^{*} & =a \cdot m \cdot \operatorname{ch}(m \cdot \cos \alpha) \cos \alpha \cdot \sin (m \cdot \sin \alpha)+ \\
& +a \cdot \operatorname{sh}(m \cdot \cos \alpha) \times \\
\times & {[-\sin (m \cdot \sin \alpha)+m \cdot \sin \alpha \cdot \cos (m \cdot \sin \alpha)], } \\
Y_{2}^{*} & =a \cdot m \cdot \operatorname{ch}(m \cdot \cos \alpha) \cdot \cos \alpha \cdot \cos (m \cdot \sin \alpha)- \\
& \quad-a \cdot \operatorname{sh}(m \cdot \cos \alpha) \times \\
\times & {[\cos (m \cdot \sin \alpha)+m \cdot \sin \alpha \cdot \sin (m \cdot \sin \alpha)], }
\end{aligned}
$$$$
Z_{2}^{*}=u \text {. }
$$

The coefficients of the first quadratic form of minimal surface (25) and the associated surface (26) found by formula (11) equal to:

$$
E=G=\operatorname{ch}^{2}\left[\sqrt{2}\left(\frac{u^{2}+v^{2}}{a^{2}}\right)^{\frac{1}{4}} \cos \left(\frac{1}{2} \operatorname{arctg} \frac{v}{u}\right)\right],
$$

$F=0$.

The coefficients (27) of the first quadratic form of minimal surface are different from coefficients (20). For a plane curve given by complex value curvature $k(s)=\frac{i}{\sqrt{2 a \cdot i \cdot s}}$, it is possible to find coefficients of the first quadratic form of corresponding minimal surfaces.

The coefficients of the second quadratic form of minimal surfaces (25), (26) coincide with the coefficients of the minimal surfaces (18), (19), using the change of variables $u$ to $v$.

The minimal surfaces (25), (26) have different metric properties with minimal surfaces (18), (19) respectively, but they have common properties of surface curvature.

\section{Conclusions}

1. The proposed method of finding isotropic curves parametric equations based on the logarithmic spiral and evolvent of circle with complex curvature allows to determine analytical description of one-parameter set of associated minimal surfaces formed under their continuous bending.

2. It is investigated that minimal surface and associated minimal surface, which are formed on the basis of a isotropic line using logarithmic spiral with curvature of the complex value share common properties of curvature with appropriate surfaces built using logarithmic spiral curvature of the real value. Using various methods of analytical description of isotropic lines with the help of evolvent of circle with curvature of complex value, minimal surfaces that with the replacement of variables have common properties of a curvature, but different metric characteristics were constructed.

3. Parametric equations of minimal surfaces were found in the form of elementary functions, which allows to explore their geometric properties and differential characteristics to optimize engineering methods to design technical forms and architectural constructions. 


\section{References}

1. Pilipaka S. F., Babka V. N., Zaharova T. N. (2013). Constructing of flat curves in polar system of coordinates according to set properties at rotation around them pole. MOTROL. Commission of Motorization and Energetics in Agriculture. Lublin, Vol. 15, No 3. 163 170.

2. Pilipaka S. F., Nesvidomin A. V., Zaharova T. N. (2013). Form of axis of flexible incompressible bar at its pushing on rough ramp with permanent speed. MOTROL. Commission of Motorization and Energetics in Agriculture. Lublin, Vol. 15, No 4. 198-205.

3. Pylypaka S., Kremetz Ya., Kresan T. (2015). Projection of a mouldboard from a ruled surface on the set geodesic curve - a limiting mechanical trajectory of a seam. MOTROL. Commission of Motorization and Energetics in Agriculture. Lublin, Vol. 17, No 3. 104 118.

4. Pilipaka S. F., Grishhenko I. Ju., Pilipaka T. S. (2010). The study of motion of particles on the inner surface of the inclined cylinder that rotates on its axis. MOTROL. Motoryzacja i energetyka rolnictwa. Tom 12B. Lublin. 115-120.

5. Klendiy N., Pilipaka S. (2015). The particle motion on the internal rough surface of a rotating cone with vertical axis. MOTROL. Commission of Motorization and Energetics in Agriculture. Lublin, Vol. 17, No 3. 73-83.

6. Nesvidomin V. N., Pylypaka T. S., Kremetz T. S. (2014). Method of analytical mapping of flat images onto curvilinear surfaces. MOTROL. Commission of Motorization and Energetics in Agriculture. Lublin, Vol. 16, No 3. 58-65.

7. Klyachin A. A., Truhlyaeva I. V. (2016). On convergence of polynomial solutions of minimal surface. Ufa Mathematical Journal, 8(1), 68-78.

8. Klyachin A. A., Panchenko A. G. (2016). Modeling minimum triangulated surfaces: error estimation calculating the area of the design of facilities. Science Journal of Volgograd State University. Mathematics. Physics, 3(34), 73-83.

9. Abdyushev A. A., Miftakhutdinov I. Kh., Osipov P. P. (2009). Design of shallow shells minimal surface. Kazan State University of Architecture and Engineering news, 2 (12), 86-92.

10. Bukhtyak M. S. (2017). Generalization of minimal surfaces and simulation of the shape of an orthotropic material construction. Tomsk state university journal of mathematics and mechanics, 45, 5-24.

11. Pylypaka S. F., Mukvich M. M. (2016). Construction a minimal surfaces using isotropic curves lying on the surfase of a torus. MOTROL: International Journal on Operation of Farm and Agri-Food Industry Machinery, 18(3), 101-110.

12. Pylypaka S. F., Mukvich M. M., (2016). Analytical description isotropic line on surface pseudosphere and construction minimal surfaces. Scientific herald of national university of life and environmental sciences of Ukraine. Series: Technique and energy of APK, 254, 202-210.

\section{Список літератури}

1. Pilipaka S. F., Babka V. N., Zaharova T. N. Constructing of flat curves in polar system of coordinates according to set properties at rotation around them pole. MOTROL. Commission of Motorization and Energetics in Agriculture. Lublin, 2013. Vol. 15, No 3. P. 163-170.

2. Pilipaka S. F., Nesvidomin A. V., Zaharova T. N. Form of axis of flexible incompressible bar at its pushing on rough ramp with permanent speed. MOTROL. Commission of Motorization and Energetics in Agriculture. Lublin, 2013. Vol. 15, No 4. P. 198-205.

3. Pylypaka S., Kremetz Ya., Kresan T.. Projection of a mouldboard from a ruled surface on the set geodesic curve - a limiting mechanical trajectory of a seam. MOTROL. Commission of Motorization and Energetics in Agriculture. Lublin, 2015. Vol. 17, No 3. P. 104-118.

4. Pilipaka S. F., Grishhenko I. Ju., Pilipaka T. S.. The study of motion of particles on the inner surface of the inclined cylinder that rotates on its axis. MOTROL. Motoryzacja i energetyka rolnictwa. Tom 12B. Lublin. 2010. P. 115-120.

5. Klendiy $N$., Pilipaka $S$. The particle motion on the internal rough surface of a rotating cone with vertical axis. MOTROL. Commission of Motorization and Energetics in Agriculture. Lublin, 2015. Vol. 17, No 3. P. 73-83.

6. Nesvidomin V. N., Pylypaka T. S., Kremetz T. S. Method of analytical mapping of flat images onto curvilinear surfaces. MOTROL. Commission of Motorization and Energetics in Agriculture. Lublin, 2014. Vol. 16, No 3. P. 58-65.

7. Klyachin A. A., Truhlyaeva I. V. On convergence of polynomial solutions of minimal surface. Ufa Mathematical Journal, 8(1), 2016. P. 68-78.

8. Клячин А. А., Панченко А. Г. Моделирование минимальных триангулированных поверхностей: оценка погрешности расчета площади проектирования объектов. Научный журнал Волгоградского государственного университета. Математика. Физика, 3(34), 2016. С. 73-83.

9. Абдюшев А. А., Мифтахутдинов И. Х., Осипов П. П. Конструкция неглубоких оболочек минимальной поверхности. Казанский государственный университет архитектуры и инженерных новостей, 2 (12), 2009. С. 86-92.

10.Бухтяк M. C. Обобщение минимальных поверхностей и моделирование формы конструкции ортотропного материала. Вестник Томского государственного университета по математике и механике, 45, 2017. С. 5-24.

11. Pylypaka S. F., Mukvich M. M. Construction a minimal surfaces using isotropic curves lying on the surfase of a torus. MOTROL: International Journal on Operation of Farm and Agri-Food Industry Machinery, 18(3), 2016. P. 101-110.

12. Pylypaka S. F., Mukvich M. M. Аналітичний опис ізотропної лінії на поверхневій псевдосфері та будівельних мінімальних поверхнях. Науковий вісник Національного університету біоресурсів та природокористування України. Серія: техніка та енергетика АПК №254, 2016. С. 202-210. 


\section{БЕЗПЕРЕРВНЕ ВИГОТОВЛЕННЯ МІНІМАЛЬНИХ ПОВЕРХОНЬ, СФОРМОВАНИХ ЗАСОБАМИ ПЛАНОВИХ КРИВИХ КОМПЛЕКСНОЇ КРІВАТУРИ \\ С. Ф. Пилипака, М. М. Муквич}

Анотація. Зроблено аналітичний опис однопараметричного набору пов'язаних мінімальних поверхонь, утворених при їх безперервному згинанні, використовуючи складну змінну. Для пошуку рівняння ізотропних ліній були використані параметричні рівняння логарифмічної спіралі та еволюції кола, визначені функціями природного параметра зі складною кривизною. Параметричні рівняння ізотропних ліній виходять із умови диференціальної дуги рівності просторової кривої до нуля. Аналітичний опис мінімальних поверхонь та 3'єднаних мінімальних поверхонь був зроблений у складному просторі 3 ізотропними лініями передачі сітки.

Знайдено вирази першої та другої квадратичних форм утворених мінімальних коефіцієнтів поверхонь. Показано, що середня кривизна утворених мінімальних поверхонь дорівнює нулю у всіх точках.

Ми досліджували, що мінімальна поверхня та пов'язана мінімальна поверхня, які формуються на основі ізотропної лінії за допомогою логарифмічної спіралі із кривизною складного значення, поділяють загальні властивості 3 відповідними поверхнями кривизни, побудованими за допомогою логарифмічної спіральної кривизни фактичної величини. Використовуючи різні методи аналітичного опису ізотропних ліній 3 розвитком кола 3 кривизною складного значення, були побудовані мінімальні поверхні, які при заміні змінної мають спільні властивості 3 кривизною, але різні метричні характеристики.

Аналітичний опис однопараметричного набору пов'язаних мінімальних поверхонь дозволяє контролювати їх форму для вирішення різних застосувань. Параметричні рівняння мінімальних поверхонь були знайдені у вигляді елементарних функцій, що дозволяють дослідити їх геометричні властивості та диференціальні характеристики для оптимізації інженерних методів проектування технічних форм та архітектурних конструкцій.

Ключові слова: однопараметричний набір асоційованих мінімальних поверхонь, ізотропна лінія, логарифмічна спіраль, еволюція кола, функція складної змінної, комплексна кривизна, середня кривизна поверхні.

\section{НЕПРЕРЫВНОЕ ИЗГОТОВЛЕНИЕ МИНИМАЛЬНЫХ ПОВЕРХНОСТЕЙ, СФОРМИРОВАННЫХ СРЕДСТВАМИ ПЛАНОВЫХ КРИВЫХ КОМПЛЕКСНОЙ КРИВАТУРЫ С. Ф. Пилипака, Н. Н. Муквич}

Аннотация. Выполнено аналитическое описание однопараметрического набора связанных минимальных поверхностей, сформированных при их непрерывном изгибе, с использованием сложной переменной. Для нахождения уравнения изотропных линий были использованы параметрические уравнения логарифмической спирали и эвольвенты окружности, определяемые функциями натурального параметра со сложной кривизной. Изотропные линии параметрических уравнений получены из условия дифференциальной дуги пространственной кривой, равной нулю. Аналитическое описание минимальных поверхностей и связанных минимальных поверхностей выполнено в сложном пространстве с изотропными линиями переноса сетки.

Найдены выражения первой и второй квадратичных форм сгенерированных коэффициентов минимальных поверхностей. Показано, что средняя кривизна сформированных минимальных поверхностей равна нулю во всех точках.

Мы исследовали, что минимальная поверхность и связанная минимальная поверхность, которые сформированы на основе изотропной линии с помощью логарифмической спирали с кривизной сложного значения, имеют общие свойства с соответствующими кривизнами поверхностей, построенных с использованием логарифмической спиральной кривизны действительного значения. Используя различные методы аналитического описания изотропных линий с выделением окружности с кривизной комплексного значения, были созданы минимальные поверхности, которые при замене переменной имеют общие свойства с кривизной, но были построены различные метрические характеристики.

Аналитическое описание однопараметрического набора связанных минимальных поверхностей позволяет контролировать их форму для решения различных задач. Параметрические уравнения минимальных поверхностей были найдены в виде элементарных функций, позволяющих исследовать их геометрические свойства и дифференциальные характеристики, оптимизировать инженерные методы проектирования технических форм и архитектурных сооружений.

Ключевые слова: однопараметрическое множество ассоциированных минимальных поверхностей, изотропная линия, логарифмическая спираль, эвольвентный круг, функция комплексной переменной, комплексная кривизна, средняя кривизна поверхности.

С. Ф. Пилипака ORCID 0000-0002-1496-4615.

М. М. Муквич ORCID 0000-0003-0979-4671. 
